\title{
Acupuncture and electroacupuncture in the treatment of laminitis in racing horses: A comparative study
}

\author{
A.I. Aljobory ${ }^{\mathbb{D}}$, S.E. Jaafar ${ }^{\mathbb{D}}$ and A.S. Ahmed \\ Department of Medical Laboratory Technique, Technical College of Kirkuk, Northern Technical University, Iraq
}

\begin{tabular}{l} 
Article information \\
\hline Article history: \\
Received October 21, 2019 \\
Accepted December 12, 2019 \\
Available online September 9, 2020 \\
\hline Keywords: \\
Acupuncture \\
Electroacupuncture \\
Lameness \\
Laminitis \\
Racing horses
\end{tabular}

Correspondence:

A.I. Aljobory

abdulmuniem@ntu.edu.iq

\begin{abstract}
This study was designed to compare the efficiency of using conventional acupuncture (CA) and electroacupuncture (EA) in the laminitis therapy in race horses, twenty adult race horses with laminitis were randomly selected. Clinical examination was carried out and acupuncture points were determined according to the results of diagnostic palpation of acupuncture. The horses were grouped into two equal groups; the 1st group was treated daily for 6 consecutive weeks, with CA and the 2nd group with EA. evaluation of lameness was depended on the visual and objective examination using the "American Association of Equine Practitioners" (AAEP) lameness scale and confidence stride lengths criterion for forelimbs which performed by the force plate indices. The lameness level was statistically analyzed applying t-test and Wilcoxon signed-rank analysis and p-value $(\mathrm{P}<0.05)$ was significant. Both visual and objective lameness examinations showed gradual statistical significant reduction $(\mathrm{P}<0.05)$ in the severity of lameness and improvement in the gait of the horses after CA and EA treatment. It is also showed that the lameness level was significantly $(\mathrm{P}<0.05)$ decreased after every weekly session of EA treatment in comparison with CA treatment. It is concluded that continued EA treatment by current study pattern showed a marked improvement in the movement of the laminitic horses when compared with CA treatment.
\end{abstract}

DOI: 10.33899/ijvs.2019.126217.1263, @2021, College of Veterinary Medicine, University of Mosul.

This is an open access article under the CC BY 4.0 license (http://creativecommons.org/licenses/by/4.0/).

\section{Introduction}

Laminitis (Founder) is a common and severe disease in the horses (1). It's a complicated and interrelated sequence of inflammatory events and severely debilitating disease caused by inflammatory and pathologic changes of the laminar conjunction which offer the connection between the external hoof layer and $3^{\text {rd }}$ phalanx (2). Several structures along with dermo-epidermal junction, basement membrane, connective tissue of the laminar dermis, and the $3^{\text {rd }}$ phalanx are affiliated with the laminar architecture (3). When the laminar conjunction is disrupted and injured, the hoof-distal phalanx bond fails and laminitis arises (4). Impaired attachment between the external hoof layer and $3^{\text {rd }}$ phalanx cannot hold off the horse weight and ground reaction forces, leading to shearing and damaging the laminae and associated vasculature, drowning and/or circumvolution of the $3^{\text {rd }}$ phalanx; crushing the corium of the sole and coronet; and resulting in excruciating ache and lameness (5). The advancement of pathological changes can include fractious pain and foot deformation, may be career-ending, and ultimately result in the horse's demise. Various mechanisms including metabolic, mechanical and nutritional theories were introduced in spite of the laminitis etiology and pathogenesis have not been completely enlightening. (6). Thus, the treatment options are multifarious and directed at different components of the known pathophysiologic processes for achieving desired outcomes (7). While allopathic medicine has not been very successful in treating laminitis, there is circumstantial evidence that acupuncture 
reduces animal's lameness and suffering; however, evidenced-based scientific investigations are rare (8). Acupuncture has been widely applied as a complementary handling choice in human and veterinary medicine to produce analgesic effects, normalize physiologic functions, and treat clinical disorders (9).

Recently Kim et al. (10), showed that acupuncture therapy has been generally used in the veterinary medicine as a complementary treatment to chronic pain, inflammation and systemic disorders like equine laminitis. Acupuncture may be characterized as the stimulant of a definitive point on the body, known as an acupuncture point, or acupoint, with a specific method, resulting in a therapeutic effect (11).

The source of this treatment can be tracked to China as beginning as 2,200 to $3,000 \mathrm{BC}$. Historically, veterinary practitioners have used conventional acupuncture, bleeding needles, heat, cauterization and massage to provoke acupoints (12). Modern technology can also be used to excite acupoints, for instance electricity, laser, microwaves and injectable agents (13). Electro-acupuncture (EA) is a technique in which an electric current is passed to the animal through inserting a needle in an acupoint (14). The EA is generally considered to have stronger effects than other types of acupuncture methods and it has been adduced to be active for the laminitis treatment (15). It was hypothesized that acupuncture would reduce lameness severity in laminitic horses, for that many studies have lately concentrated on the impact of electroacupuncture in treating various aspects of equine illnesses like musculoskeletal, gastrointestinal, respiratory, and disorders of the reproductive system (16). Nevertheless, there is a lack of evidence-based research supporting the comparison between conventional acupuncture (CA) and EA in treating laminitis. So this investigation was intended to compare the efficiency of CA and EA in the laminitis treatment in racing horses.

\section{Materials and methods}

\section{Animals}

Twenty adult race horses aged between 18-22 years with laminitis from one geographical area were selected and initial degree of lameness, and lameness duration were recorded from $1 / 7 / 2019$ to $1 / 10 / 2019$.

\section{Lameness evaluation}

An objective evaluation of lameness was conducted using a wireless, body-mounted inertial gyroscope and accelerometer system called the "Lameness Locator" (Equinosis LLC, St. Louis, Missouri, USA). Three small wireless sensors were mounted on the horse's body. One axial accelerometer was mounted on the head and one on the pelvis, while a single-axial gyroscope was placed on the dorsal aspect of the right front pastern (17). The wireless data from the vertical expedition of the head and pelvis and angular speed of the right forelimb were collected using a laptop computer, analyzed, and reported as 'Vector Sum' $(18,19)$. Additionally, Davidson (20) reported that lameness severity was evaluated at the same day by: a routine visual lameness examination following "American Association of Equine Practitioners" (AAEP) recommended 0 to 5 grading system as shown in table 1 . Stride length measurements and force plate measurements. Lameness examination was performed before the $1^{\text {st }}$ week and next the CA and EA treatment. To ensure consistency and accuracy, the lameness evaluation was replicated three times for each horse and the arithmetic mean was calculated and used for statistical analyses.

The lengths of stride were measured when the animal walking above the sand-pit. The distance between the front edges of the imprint of each front leg was measured between successive strides. Five measurements were made to obtain (mean $\pm \mathrm{SD}$ ). Horses were led at a walk over the force plate which was mounted in a concrete walkway and concealed under the carpet. Responses for the four legs were recorded with an FM magnetic tape recorder (Model 3964A, Hewlett Packard, Palo Alto, California) for later analysis by a digital computer (Model PDP-12, Digital Equipment Corp, Maynard, Massachusetts) programmed to measure the maximal amplitude of the responses. The first five acceptable waveforms were utilized to obtain the (mean $\pm \mathrm{SD}$ ) for the maximal amplitude. The weight distribution percentage (\%) between the four legs was calculated from the maximal amplitude values by mean for one leg/ summed mean for all legs $\times 100$. The normal weight distribution is $30 \%$ and $20 \%$ for the front and hind legs, respectively; with this equation (21). The ultimate value at which every limb differed from these normal values was calculated and the four values were summed. This value was the "force plate index." Evaluation of all limbs was considered necessary since the lameness shifted in some horses.

Table 1: Clinical grading system of foreleg lameness (22)

\begin{tabular}{cl}
\hline Grade & Observation \\
\hline 0 & No lameness \\
1 & Subtle lameness -heel-toe gait \\
2 & Slight lameness -heel-toe gait and stiffness \\
3 & Moderate lameness - walks camped out \\
4 & Moderate lameness - effort when moving \\
5 & Sever lameness - effort to initiate movement \\
\hline
\end{tabular}

\section{Acupuncture treatments}

Acupuncture therapy consisted of electric stimulation at acupuncture tips upon the front limbs that have been suggested for the therapy of laminitis (15). An examination of a diagnostic acupuncture palpation was performed on all horses and appropriate acupuncture points were chosen before each treatment. Starting from the $1^{\text {st }}$ week of study, electroacupuncture was applied for 20 minutes. Each horse 
in every treatment groups performed day-after-day for six consecutive weeks.

Lee and Faramarzi (23) clearly explained conventional acupuncture methods which included: dry needling, hemoacupuncture, and aqua-acupuncture contingent on the problem nature and the treated acupuncture points area. For consistency, hemo-acupuncture (Small Intestine-1, Triple Heater-1, Large Intestine-1, QIAN-TI-TOU, and QIAN-TITOU mirror points) and dry needling (Heart-9, Pericardium9, Lung-11, and QIANTI-MEN points) as shown in figure-1.

The points used for laminitis resembling points $100-117$ at the forelimb and $140-149$ at the hind limbs as shown in figure 2. These points are located caudal to the shoulder joint, caudal to the proximal metacarpal bone on the lateral aspect overlying the lateral palmar nerve, ventral and dorsal to the medial and lateral sesamoid bones, and on the foot. The probe of an acupuncture point finder (Hibiki-7 Acupuncture Point Finder, Asahi Corp., Japan) was moved over the skin until the point of decreased electric resistance was found (24).

The points were marked with indelible ink and all parameters were measured weekly.

(a)

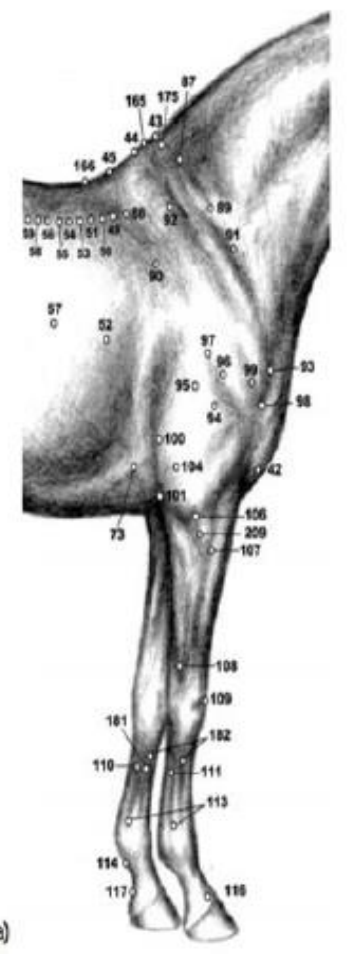

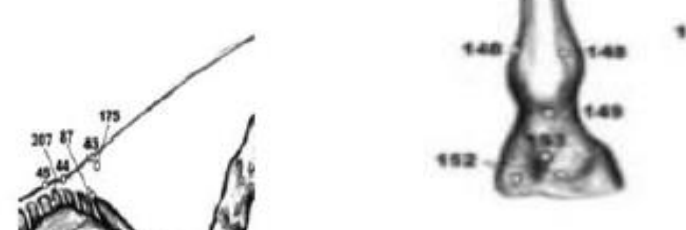

Figure 2: Acupoints of hind limbs (From the caudal view) (24).

\section{Results}

Assessment of the lameness levels after the CA and EA treatments were demonstrated in figures 3 and 4 both visual (following AAEP lameness grading) and objective (Lameness Locator) lameness examinations showed gradual statistical significant reduction $(\mathrm{P}<0.05)$ in the lameness severity and improvement in the gait of horses started at $4^{\text {th }}$ week after treatment and the decreasing continued significantly in $5^{\text {th }}$ and $6^{\text {th }}$ weeks. However, visual lameness examinations in figure 3 indicated a significant decrease $(\mathrm{P}<0.05)$ in AAEP grading in EA group 2.2 at $5^{\text {th }}$ week and decreased to 1.3 at the $6^{\text {th }}$ week, and simultaneously, remarkable significant difference $(\mathrm{P}<0.05)$ had been noticed in comparing with the averages of $\mathrm{CA}$ group at $5^{\text {th }}$ and $6^{\text {th }}$ weeks. In figure 4 objective lameness examination means, showed significant reduction $(\mathrm{P}<0.05)$ in lameness severity at fifth and sixth weeks at EA group when compared with the criteria at CA treated horses which reduced to 22.4 and 16.7, respectively. It also revealed significant decreasing $(\mathrm{P}<0.05)$ at last two weeks of this study in relative to other weeks. The stride lengths and force plate index averages revealed significant gradual improvement $(\mathrm{P}<0.05)$ in CA and EA in 
the left and right forelimb especially at the last three weeks (Figure 5 and 6).

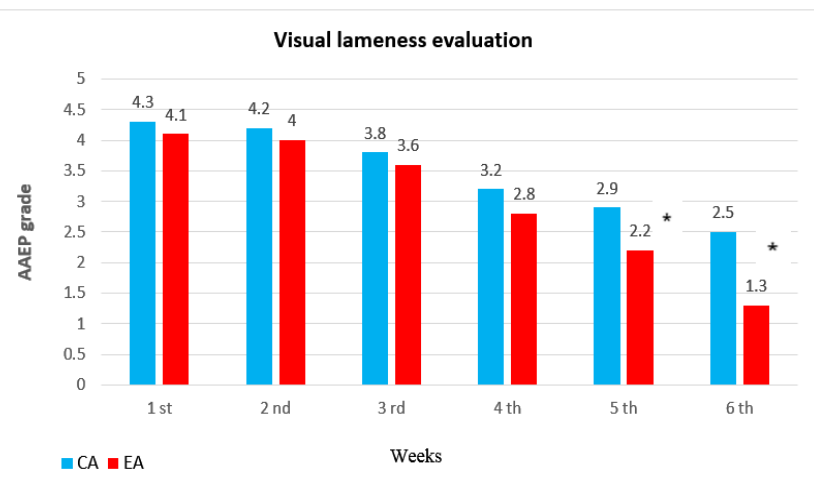

Figure 3: Comparison of the lameness level difference between (CA) and (EA) treatment by visual (AAEP grading) lameness evaluation (mean $\pm \mathrm{SD}$ ). P-values $<0.05$ were statistically significant.

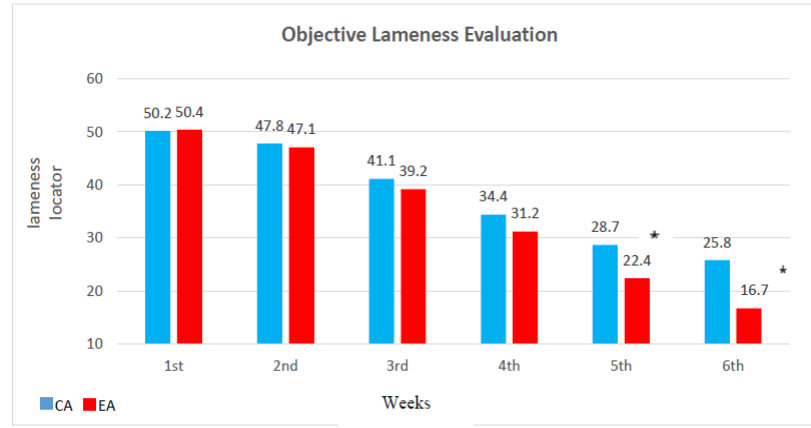

Figure 4: Comparison of the lameness level difference between CA and EA treatment by objective (lameness locator) lameness evaluation (mean $\pm \mathrm{SD}$ ). P-values $<0.05$ were statistically significant. $* \mathrm{P}<0.05$.
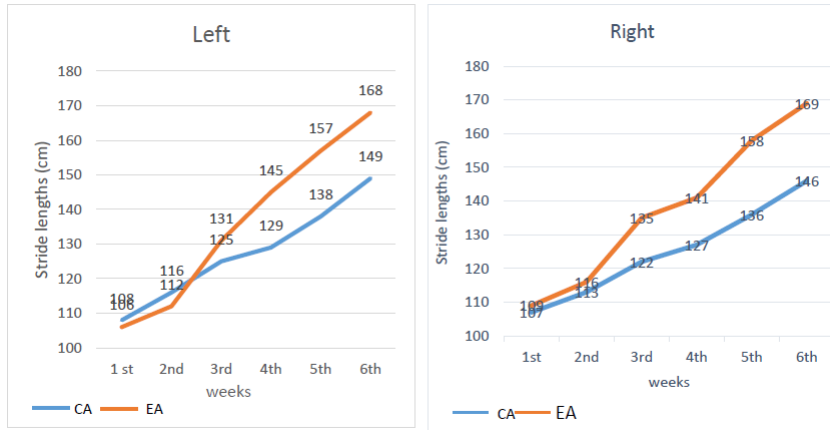

Figure 5: Stride lengths (mean $\pm \mathrm{SD}$ ) for conventional acupuncture (CA) and electroacupuncture (EA) for left and right forelimb treated horses.

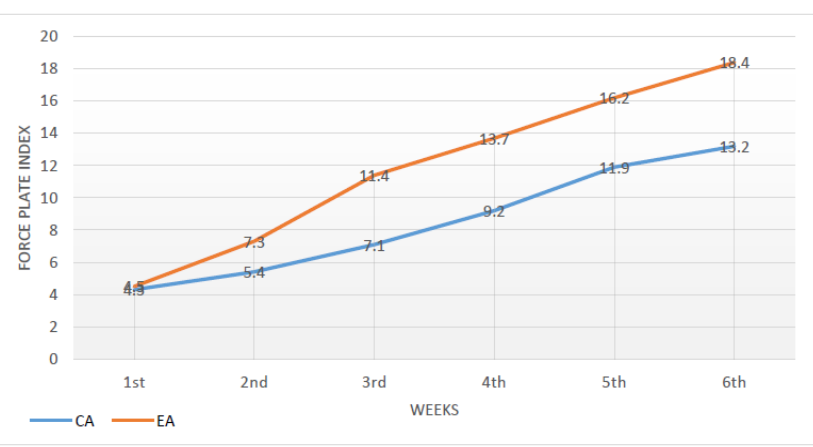

Figure 6: Force plate indices (mean $\pm \mathrm{SD}$ ) for conventional acupuncture (CA) and electroacupuncture (EA) forelimb treated horses. P-values $<0.05$ were considered statistically significant.

\section{Discussion}

Veterinary literatures suggested that musculoskeletal diseases are responsive to acupuncture (25). Prescribed acupuncture points for treating laminitis have been portrayed (26). The laminitis treatment is multifaceted because of the complication of the laminitis and its pain. The objective of the treatment is to manage the pain and prevent a recurrence. Our study compared the response of lameness of racing horses to electroacupuncture treatment with conventional acupuncture; the outcomes uncovered that applying to EA treatment further decreased the lameness rigor in racing horses with laminitis.

We found that the lameness horses significantly improved after the (EA) treatment more idealistic and convened in comparing with $\mathrm{CA}$. The management of lameness through controlling the pain in laminitic horses is a key element for determining prognosis and rehabilitation. Available treatments for laminitis are very limited, especially EA, mainly because of limited existing knowledge of the etiology and pathophysiology of the disease (27). Although several treatment options have been suggested to manage laminitis, they are influenced by the time and effort needed for application and by side effects (28). In a previous study reported by Parsons et al. (29) that $19 \%$ of laminitic horses referred to veterinary teaching hospitals suffered from permanent lameness, while $48 \%$ were eventually euthanized.

The neurophysiological mechanisms of acupuncture analgesia have been recorded and included: opiate and nonopiate pain modulation, hippocampal nitric oxide synthase activity, and the expression of various mediators of neurologic inflammation have been documented as well. (10).

Acupuncture provides a drug-free and safe alternative treatment with minimum side effects and rare adverse reactions (30). Acupuncture influences multiple systems which are usually involved in the laminitis development, such as musculoskeletal, gastrointestinal and immune 
systems (31). It has been recommended that acupuncture prevents and modifies the perception of pain at many various degrees of the nervous system including a raise in opioid peptides secretion, oxytocin concentration and serotonin receptors activation $(32,33)$. In the present study, we used hemo-acupuncture as part of our treatment formula for all horses. Hemo-acupuncture causes bleeding at acupoints and is related to the phlebotomy effect, which might relieve extravasated blood stagnation and therefore improve local circulation (34).

Laminitis is linked to hypoperfusion, ischemia and necrosis of lamellae (35). It has been stated that destruction of the lamellar basement membrane is associated with activation and deactivation of metalloproteinases (MMPs), including MMP-9 and MMP-2 as well ADAMs (a disintegrin and metalloproteinases), originally also known as MDC proteins (metalloproteinase /disinterring/ cysteine -rich) with thrombospondin motifs-4 (ADAMTS-4); which are well significant in the laminitis development (36).

Moreover, earlier studies described that acupuncture inhibits expression and activation of metalloproteinases (MMPs) 2 and 9 that are associated with chronic laminitis (37). Hence, acupuncture may not only improve the immediate clinical signs, but may also prevent the progression and recurrence (e.g., the occurrence of acute episodes) of laminitis (38); yet, more research is warranted. The complex nature of laminitis and the acupuncture likelihood influence on several body systems suggest acupuncture as an appropriate ancillary treatment (39). Furthermore, acupuncture therapy does not interfere with other treatments such as therapeutic shoeing, medications, dietary restrictions; thus, it can be offered in parallel with other acute and chronic laminitis therapies (40). Acupuncture increases the synthesis of nitric oxide (NO) activity around acupoints (41).

The nitric oxide is a regulator key of local circulation and may improve local circulation of L-arginine and glyceryl trinitrate (42). Local impacts of acupuncture, including pain relief, alteration in local circulation, and mediation of inflammation, are associated with the increase of calcitonin peptide and synthesis of nitric oxide activity (NO) (43). Therefore, it is probable that acupuncture treatment improves lameness through pain modulation and local circulation, as well as preventing the exacerbation and relapse of laminitis (44).

Acupoints are central areas of decreased electrical resistance that are shared to specific anatomic locations; those points are associated with high concentrations of autonomic innervation, vacuolization, and lymphatic drainage/vessels within the fascia and muscles (45). Most of the acupoints that were used in the current study, involving HT-9, SI-1, TH-1, LI- 1, LU-11, PC-9, and QIAN-TI-MEN, have been prescribed by past studies (21). It has been suggested to use of QIAN-TI-TOU and its mirror points in the hoof pain therapy (46). The addition of QIAN-TI-TOU and its mirror points were deemed beneficial as local toe points to remedy the pain in laminitic patients.

\section{Conclusion}

From our results we concluded that there was a significant improvement in the movement of the horses with laminitis after continued electroacupuncture treatment when compared with conventional acupuncture treatment.

\section{Acknowledgments}

We would like to acknowledge all veterinary staff and nurses for their assistance and facility during animal handling.

\section{Conflict of interest}

The authors declared that there is no conflict of interest.

\section{References}

1. Robertson TP, Bailey SR, Peroni J. Equine laminitis: A journey to the dark side of venous. Vet Immunol Immunopathol. 2009;129(3-4):16466. Doi: $\underline{10.1016 / j . v e t i m m .2008 .11 .015}$

2. Wylie CE, Collins SN, Verheyen KL, Newton JR. Risk factors for equine laminitis: A systematic review with quality appraisal of published evidence. Vet J. 2012;193(1):58-66. Doi: 10.1016/j.tvjl.2011.10.020

3. Thomason JJ, Douglas JE, Sears W. Morphology of the laminar junction in relation to the shape of the hoof capsule and distal phalanx in adult horses (Equus caballus). Cells Tissues Organs. 2001;168(4):295-311. Doi: 10.1159/000047846

4. Kochová P, Witter K, Cimrman R, Mezerová J, Tonar Z, A preliminary study into the correlation of stiffness of the laminar junction of the equine hoof with the length density of its secondary lamellae. Equine Vet J. 2013;45(2):170-5. Doi: 10.1111/j.2042-3306.2012.00632.x

5. Hood DM. Laminitis in the horse. Vet Clin North Am Equine Pract. 1999;15(2):287-294. Doi: 10.1016/s0749-0739(17)30145-1

6. Engiles JB, Galantino HL, Boston R, McDonald D, Dishowitz M, Hankenson KD. Osteopathology in the equine distal phalanx associated with the development and progression of laminitis. Vet Pathol. 2015;52(5):928-44. Doi: 10.1177/0300985815588604

7. Bamford NJ. Clinical insights: Treatment of laminitis. Equine Vet J. 2019;51(2):145-146. Doi: 10.1111/evj.13055

8. Fry LM, Neary SM, Sharrock J, Rychel JK. Acupuncture for analgesia in veterinary medicine. Top Companion Anim Med. 2014;29(2):35-42. Doi: 10.1053/j.tcam.2014.003.001

9. Walsh DM. Laminitis treatment: A personal memoir. Vet Clin North Am Equine Pract. 2010;26(1):21-8. Doi: 10.1016/j.cveq.2010.01.004

10. Kim KW, Park K, Park HJ, Jahng GH, Jo DJ, Cho JH, Song EM, Shin WC, Yoon YJ, Kim SJ, Eun S, Song MY. Effect and neurophysiological mechanism of acupuncture in patients with chronic sciatica: protocol for a randomized, patient-assessor blind, sham-controlled clinical trial. Trials. 2019;20(1):56. Doi: 10.1186/s13063-018-3164-8

11. Lancaster LS, Bowker RM. Acupuncture points of the horse's distal thoracic limb: A neuroanatomic approach to the transposition of traditional points. Anim. 2012;2(3):455-471. Doi: 10.3390/ani2030455

12. Zhu H. Acupoints initiate the healing process. Med Acupunct. 2014;26(5):264-270. Doi: 10.1089/acu.2014.1057

13. Xie H, Colahan P, Ott E.A. Evaluation of electroacupuncture treatment of horses with signs of chronic thoracolumbar pain. J Am Vet Med Assoc. 2005;227(2):281-6. DOI: $\underline{10.2460 / 2005.227 .281}$ 
14. Zhang R, Lao L, Ren K, Berman BM. Mechanisms of acupunctureelectroacupuncture on persistent pain. Anesthesiol. 2014;120(2):482503. Doi: $10.1097 /$ ALN.0000000000000101

15. Faramarzi B, Lee D, May K, Dong F. Response to acupuncture treatment in horses with chronic laminitis. Can Vet J. 2017;58(8):823827. Doi: 10. .C5508962

16. Le Jeune S, Henneman K, May K. Acupuncture and equine rehabilitation. Vet Clin N Am Equine. 2016;32:73-85. Doi: 10.1016/j.cveq.2015.12.004

17. Keegan KG, Kramer J, Yonezawa Y, Maki H, Pai PF, Dent EV, Kellerman TE, Wilson DA, Reed SK. Assessment of repeatability of a wireless, inertial sensor-based lameness evaluation system for horses. Am J Vet Re. 2011;72:1156-1163. Doi: 10.2460/ajvr.72.9.1156

18. McCracken MJ, Kramer J, Keegan KG, Lopes M, Wilson DA, Reed SK, LaCarrubba A, Rasch M. Comparison of an inertial sensor system of lameness quantification with subjective lameness evaluation. Equine Vet J. 2012;44:652-656. Doi: 10.1111/42-3306.2012.00571.X

19. Keegan KG, Wilson DA, Kramer J, Reed SK, Yonezawa Y, Maki H, Pai PF, Lopes MA. Comparison of a body-mounted inertial sensor system-based method with subjective evaluation for detection of lameness in horses. Am J Vet Res. 2013;74:17-24. Doi: 10.2460/ajvr.74.1.17

20. Davidson EJ. Lameness evaluation of the athletic horse. Vet Clin North Am Equine Pract. 2018;34(2):181-191. Doi: 10.1016/04.013

21. Steiss JE, White NA, Bowen JM. Electroacupuncture in the treatment of chronic lameness in horses and ponies: A controlled clinical trial. Can J Vet Res. 1989;53:239-243. Doi: 10.1255553

22. Taylor D, Hood DM, Wagner IP. Short-term effect of therapeutic shoeing on severity of lameness in horses with chronic laminitis. Am J Vet Res. 2002;63:1629-1633. Doi: 10.2460/ajvr.2002.63.1629

23. Lee D, May K, Faramarzi B. Comparison of first and second acupuncture treatments in horses with chronic laminitis. Iran J Vet Res. 2019;20(1):9-12. Doi: 10.6509908

24. Xie H, Preast V Xie's Veterinary Acupuncture. $1^{\text {st }}$ ed. New York: Blackwell Publishing; 2007. 256-260 p.

25. Xu T, Zhou S, Zhang Y, Yu Y, Li X, Chen J, Du J, Wang Z, Zhao L. Acupuncture for chronic uncomplicated musculoskeletal pain associated with the spine. Med. 2019;98(2):e14055. Doi: 10.1094055

26. Van Eps AW. Acute laminitis: medical and supportive therapy. Vet Clin North Am Equine Pract. 2010; 6(1):103-14. Doi: 10.1016/j.cveq.2009.12.011

27. Laskoski LM, Valadão CAA, Dittrich R.L, Deconto I, Faleiros RR. An update on equine laminitis. Ciência Rural. 2016;46:547-553. Doi: 10.1590/0103-8478cr20150175

28. Carmalt JL. Equine Laminitis. Can Vet J. 2018;59(4):407. Doi: 10.5855283

29. Parsons CS, Orsini JA, Krafty R., Capewell L, Boston R. Risk factors for development of acute laminitis in horses during hospitalization: 73 cases (1997-2004). J Am Vet Med Assoc.2007; 230(6):885-9. Doi: 10.2460/javma.230.6.885

30. Robinson KA, Manning ST. Efficacy of a single-formula acupuncture treatment for horses with palmar heel pain. Can Vet J. 2015;56:12571260. Doi: $\underline{10.4668809}$

31. Lancaster LS. Medical acupuncture for equine laminitis. J Equine Vet Sci. 2011;31:604. Doi: 10.1016/j.jevs.2011.09.056

32. Han JS. Acupuncture and endorphins. Neurosci Lett. 2004;361:258261. Doi: $10.1016 /$ j.neulet.2003.12.019

33. Zhang Y, Li A, Xin J, Ren K, Berman BM, Tan M, Zhang RX. Involvement of spinal serotonin receptors in electroacupuncture antihyperalgesia in an inflammatory pain rat model. Neurochem Res. 2011;36:1785-1792. Doi: 10.1007/s11064-011-0495-1

34. Kim DH, Liu J, Choi SH, Macmanus P, Jennings P, Darcy K, Burke F, Leorald N, Rogers PA. Acupuncture treatment in a case with equine laminitis. J. Vet. Clin. 2006;23:6-8. [available here]

35. Schramme MC, Labens R. Orthopaedics S. Diseases of the foot and distal limbs. In: Mair TS, Love S, Schumacher J, Smith RK, Frazer G. Equine medicine, surgery and reproduction. $2^{\text {nd }}$ ed. Amsterdam: Elsevier Heal Science; 2013. 329-368 p.
36. Loftus JP, Johnson PJ, Belknap JK, Pettigrew A, Black SJ. Leukocyte derived and endogenous matrix metalloproteinases in the lamellae of horses with naturally acquired and experimentally induced laminitis. Vet Immunol Immunopathol. 2009;129:221-230. Doi: 10.1016/11.003

37. Cayir Y, Ozdemir G, Celik M, Aksoy H, Akturk Z, Laloglu E, Akcay F. Acupuncture decreases matrix metalloproteinase-2 activity in patients with migraine. Acupunct Med. 2014;32:376-380. Doi: 10.1136/acupmed-2014-010612

38. Uchida $S$, Hotta $H$. Acupuncture affects regional blood flow in various organs. Evid Based Complement Alternat Med. 2008;5:145151. Doi: $10.1093 /$ ecam/nem051

39. Shmalberg J, Xie $\mathrm{H}$. The clinical application of equine acupuncture. J Equine Vet Sci. 2009;29:645-652. Doi: 10.1093/ecam/nem051

40. Mama KR, Hector RC. Therapeutic developments in equine pain management. Vet J. 2019;247:50-56. Doi: 10.1016/j.tvj1.2019.02.010

41. Tsuchiya M, Sato EF, Inoue M, Asada A. Acupuncture enhances generation of nitric oxide and increases local circulation. Anesth Analg.

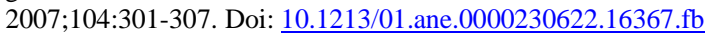

42. Bailey SR, Marr CM, Elliott J. Current research and theories on the pathogenesis of acute laminitis in the horse. Vet J. 2004;167:129-142. Doi: 10.1016/S1090-0233(03)00120-5

43. Habacher, G, Pittler MH, Ernst E. Effectiveness of acupuncture in veterinary medicine: Systematic review. J Vet Intern Med. 2006;20(3):480-488. Doi: 10.1892/0891-6640(2006)20[480:eoaivm]

44. Dunkel B, Pfau T, Fiske J, Aeres KO, Fairhurst H, Jackson K, Chang YM, Bolt DM. A pilot study of the effects of acupuncture treatment on objective and subjective gait parameters in horses. Vet Anaesth Analg. 2017;44(1):154-162. Doi: 10.1111/vaa.12373

45. Petermann U. Comparison of pre-and post-treatment pain scores of twenty-one horses with laminitis treated with acupoint and topical low level impulse laser therapy. Am J Tradit Chinese Vet Med. 2011;6:1325. [available here

46. Ricardo LP, Sampaio F, Silveira AB, Bastos LF, Weber SH, Michelotto PV. Pressuring of acupoints as a complement to the stifle diseases diagnosis in horses. J Acupunct Meridian Stud. 2019;(18):30137-7. Doi: $\underline{10.1016 / j . j a m s .2019 .06 .001}$

\section{الوخز بالإبر والإبر الكهربائية في علاج حمى الحافر في خيول السباق: دراسة مقارنة}

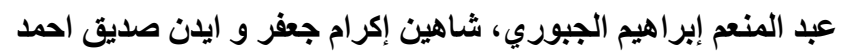

قسم تقنيات المختبرات الطبية، الكلية التقنية، كركوك، الجامعة التقنية

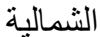

هدفت الدر اسة الحالية لدقارنة استخدام الوخز بالإبر التقليدية و الإبر

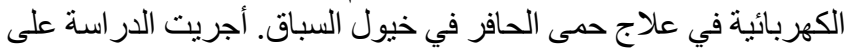

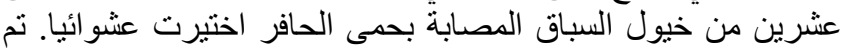

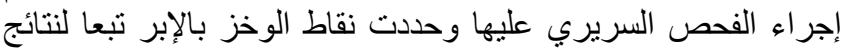

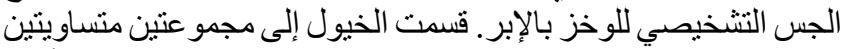

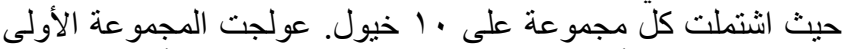

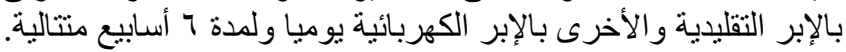

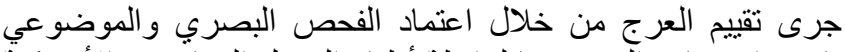

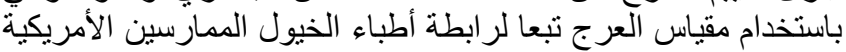

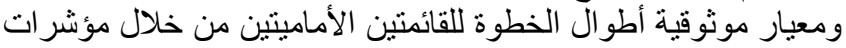

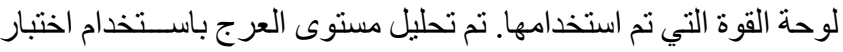


المستمر بالإبر الكهربائية حسب نمط الدراسة الحالية أدى إلى تحسن

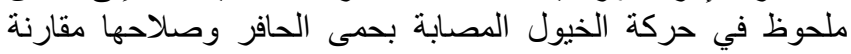
بعلاجها بالإبر التقليدية.
تي المزدوج وتحليل تصنيف موقع ويلكو كسون و اعتبرت القيمة معنوية

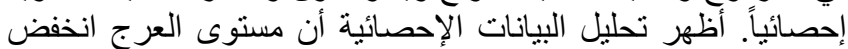

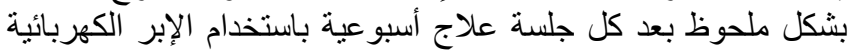
مقارنة مع العلاج باستخدام الإبر التقليدية. أنشارت النتائج إلى أن العلاج العابئ 